\title{
GESTÃO DE PROJETOS E A ABORDAGEM PRÁTICA NA EMPRESA BRASILEIRA DE INFRAESTRUTURA AEROPORTUÁRIA
}

\author{
PROJECT MANAGEMENT AND PRACTICAL APPROACH IN THE BRAZILIAN AIRPORT \\ INFRASTRUCTURE COMPANY
}

Leticia Maria Heineck Andriani Especialista em Gestão Estratégica, Inovação e Conhecimento, Escola Superior Aberta do Brasil - ESAB Coordenadora de Segurança Operacional - INFRAERO

Curitiba, Paraná - Brasi

lehandriani@yahoo.com.br

Ariel Orlei Michaloski

Doutor em Engenharia de Produção, Universidade Federal de Pernambuco - UFPE Professor da UTFPR

Ponta Grossa, Paraná - Brasil ariel@utfpr.edu.br

Jair de Oliveira

Doutor em Engenharia, Universidade de São Paulo - USP Professor da UTFPR Cornélio Procópio, Paraná - Brasi

Resumo

jair@utfpr.edu.br

Aeroportos são sistemas complexos e específicos com grande variedade de envolvidos em seus processos. Por esse motivo, a usabilidade da gestão de projetos como ferramenta de gerenciamento é importante em todas as fases dos seus projetos. Nesse toar, é notório que toda organização enfrenta a difícil tarefa de executar projetos os quais atinjam as expectativas de seus clientes. De maneira geral, vários projetos, eventualmente, fracassam, sendo concluídos fora do orçamento e dos prazos estabelecidos, além de não cumprirem as normas de qualidade e os requisitos esperados pelo cliente. O presente trabalho foi desenvolvido com base nos conceitos e técnicas que norteiam a gestão de projetos para atendimento às exigências do mercado por processos ágeis e enxutos. A proposta desta pesquisa é a demonstração real da utilização de uma metodologia de gestão de projetos otimizada e alinhada às estratégias organizacionais. Para tanto, por meio de uma pesquisa-ação em gestão de projetos e nos conceitos do PMBOK, foi estudada a implementação da metodologia desenvolvida pela INFRAERO para gerenciamento de projetos públicos, aplicada ao caso real de revitalização da pista de pouso e decolagem auxiliar do Aeroporto Internacional de Curitiba. Como resultado, na fase de racionalização do projeto, foi possível reduzir 95\% do tamanho da equipe necessária para seu gerenciamento em relação ao último grande empreendimento realizado no aeroporto, proporcionando economia equivalente, além do aumento da eficiência de cada etapa devido à redução de interferências. Dessa forma, a proposta desenvolvida atingiu seu objetivo ao apresentar a aplicação desta metodologia, contribuindo com a comunidade acadêmica.

Palavras-chave: Gerenciamento de projetos. Aeroportos. Setor público. Infraero. Infraestrutura.

\begin{abstract}
Airports are complex and specific systems with a wide variety of processes involved. For this reason, the usability in project management as a management tool is essential at all stages of projects. In this context, it is well known that every organization faces the difficult task of executing projects that can meet customer expectations. In general, many projects are unsuccessful, exceed the budget and miss the deadline, and fail to meet quality standards and requirements expected by customers. The present work was based on the concepts and techniques of underpinning project management to meet market demands for agile and lean processes. The purpose of this research is a thorough description of the use of an optimal project management methodology aligned with organizational strategies. This study focused on the implementation of the methodology developed by the Brazilian Airport Infrastructure Company (INFRAERO) for public project management, applied to the real case of secondary landing and takeoff runway redevelopment at the Curitiba International Airport. In the research, it was used action research method based on project management and PMBOK concepts. The result showed that in the project rationalization phase, the size of the staff required for management could be reduced by $95 \%$, compared to the last major venture at the airport, providing equivalent savings, as well as increasing the efficiency of each stage owing to the reduction of interference. Therefore, this research proposal reached its objective by presenting the application of this methodology, thereby contributing to the academic community.
\end{abstract}

Keywords: Project management. Airports. Public sector. Infraero. Infrastructure.

$\underline{\text { Cite como }}$

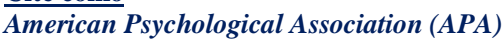

Andriani, L. M. H., Michaloski, A. O., \& Oliveira, J. de. (2021, maio/ago.). Gestão de projetos e a abordagem prática na empresa brasileira de infraestrutura Aeroportuária. Revista de Gestão e Projetos (GeP), 12(2), 192-213. https://doi.org/10.5585/gep.v12i2.16262. 


\section{Introdução}

$\mathrm{Na}$ visão dos autores, a qualidade mais almejada pelas empresas, atualmente, é a capacidade de um gestor observar, detalhadamente, tudo o que pode gerar valor ao empreendimento, sem qualquer tipo de barreira, informando-se sobre tudo o que há de mais inovador em produtividade e em gestão eficaz e eficiente. Os autores corroboram também a ideia de que, diante do cenário competitivo atual, as empresas têm almejado constantemente a excelência operacional e de qualidade para seus negócios, não podendo se descuidar, ao mesmo tempo, das questões de gestão integrada de segurança e saúde do trabalho e de meio ambiente. Nesse viés, surgem os sistemas de gestão de projetos com as certificações de gestão da qualidade, gestão ambiental e de gestão da segurança e saúde do trabalho.

Nesse contexto, empresas que querem atingir determinado nível competitivo necessitam obter e garantir o atendimento aos requisitos normativos, bem como manter-se constantemente dispostas a enfrentar riscos em busca de melhorias. Alleman (2003) afirma que $\mathrm{o}$ atendimento às estratégias corporativas pode ser obtido por meio de projetos, desde que estejam alinhados. Por sua vez, Basgal, Merotto, Martins, Catarino, Navarro e Gregório (2009) afirmam que as organizações normalmente implementam suas estratégias por meio de pacotes de projetos alinhados ao planejamento estratégico.
Diante disso, salienta-se a relevância deste estudo considerando sua pretensão de responder ao seguinte questionamento: a aplicação correta da gestão de projetos no ramo aeroportuário pode melhorar o compliance em relação à governança e ao planejamento estratégico da empresa?

Assim sendo, o objetivo é demonstrar a aplicação prática da metodologia concebida pela Infraero para gestão de projetos, utilizando como exemplo a obra de recuperação da pista de pouso e decolagem auxiliar do Aeroporto Internacional de Curitiba, tendo como finalidade analisar o processo de gestão de projetos, a fim de prover suporte à sua melhoria contínua. Ressalta-se ainda que o presente estudo priorizou a identificação e a aplicação da metodologia de gestão de projetos no referido caso em estudo.

\section{Fundamentação teórica}

Em relação aos avanços da gestão de projetos, observa-se que existem diversos métodos de avaliação disponíveis para a obtenção do nível de desempenho estratégico de uma organização. O auxílio da tecnologia é relevante para a realização de simulações de desempenho relacionadas à gestão de projetos, a partir das quais pode-se desenvolver soluções estratégicas mais próximas dos parâmetros ideais, reduzindo-se os erros de projeto ou de execução, além dos problemas relacionados ao processo de gerenciamento (Michaloski \& Costa, 2010; Michaloski, 2011). 
Na visão dos mesmos autores, a gestão de projetos é um alicerce para todo e qualquer trabalho de gestão, uma vez que as organizações precisam perceber e conhecer como elas mesmas funcionam, de que modo são realizadas suas operações, seus negócios, suas atividades e quais são suas culturas organizacionais.

A fim de embasar a metodologia que será apresentada, esta seção traz a fundamentação teórica a respeito do gerenciamento de projetos, tanto de forma abrangente quanto aplicada ao setor público, evidenciando as características que as diferenciam.

\subsection{Gerenciamento de projetos}

Projeto, segundo o Project Management Institute (2019), é um conjunto de atividades temporárias, realizadas em grupo, destinadas a produzir um produto, serviço ou resultado único. Já o gerenciamento de projetos é a aplicação de conhecimentos, habilidades e técnicas para execução de projetos de forma efetiva e eficaz.

Segundo Marcondes (2017), desde os primórdios da civilização, a humanidade executa projetos, como a construção das pirâmides do Egito, do Templo de Salomão, da Grande Muralha da China, entre diversos outros exemplos históricos. Desde esses tempos remotos, até hoje, muito se evoluiu. Porém, somente em meados do século XX, o gerenciamento de projetos passou a ser uma disciplina concebida a partir da necessidade de se sistematizar e de organizar a gestão das diferentes habilidades e conhecimentos envolvidos na execução de um projeto (Marcondes, 2017).

Para Bomfin, Nunes e Hastenreiter (2012), o projeto inicia-se a partir do surgimento de demandas que devem ser executadas para atendimento de um objetivo, o que exige esforço para geração dos resultados esperados. Dentre os principais fatores que demandam projetos em uma organização, Menezes (2001) destaca: as questões relacionadas ao produto, seja para atendimento às especificidades de um produto único, para melhoria ou para criação de um novo produto; as mudanças organizacionais, como restruturações, por exemplo; a gestão estratégica da própria organização, para implantação de suas estratégias comerciais, de produção, etc.; os prazos e recursos limitados, os quais requerem que o trabalho seja planejado como um projeto; e as necessidades de melhoria interna e aprimoramento contínuo de processos.

Essas demandas de mudanças e melhorias contínuas passaram a fazer parte da rotina das organizações que pretendem se manter competitivas em um mercado cada vez mais exigente. Cada uma dessas mudanças é um projeto, no sentido de ser um esforço temporário, que possui data de início e fim, cuja finalidade é gerar um resultado diferente do atual. E diante desse cenário, o domínio das mais modernas práticas de gerenciamento de projetos passou a ser fundamental para a sobrevivência do negócio, além da eficiência em sua execução. Saber planejar e executar 
projetos é uma necessidade real em qualquer ramo de atividade, afirma Xavier (2016).

O Guia PMBOK (Project Management Body of Knowledge) do PMI (2017), reúne conhecimentos, processos, habilidades, ferramentas e técnicas que podem ser utilizados na maioria dos projetos. É reconhecido como um guia de boas práticas de gerenciamento de projetos. O PMBOK agrupa os processos referentes ao gerenciamento de projetos em dez áreas de conhecimento: integração do projeto, escopo, cronograma, custos, qualidade, recursos, comunicações, riscos, aquisições e partes interessadas.

Essas áreas são distribuídas nas cinco etapas do ciclo de vida do projeto: iniciação, planejamento, execução, monitoramento e controle, e encerramento. Para cada uma das dez áreas de conhecimento, o PMBOK lista um conjunto de processos necessários para a sua execução, bem como as demandas de entradas e os artefatos de saídas relativos ao processo. Além disso, indica ferramentas e técnicas mais adequadas para aplicação no gerenciamento do respectivo processo.

\subsection{Cenários de gerenciamento de projetos no setor público}

Diferentemente do setor privado, as organizações públicas não têm, como foco prioritário, a competitividade para fins de sobrevivência. Mesmo assim, elas são cada vez mais exigidas quanto à melhoria contínua de seus resultados em prol da sociedade. Meneses, Oliveira e Vasconcelos (2016) observam que, diversamente das empresas privadas, para as quais o resultado almejado é o lucro, no setor público um dos principais indicadores do sucesso de um projeto refere-se ao benefício social resultante.

As diferenças entre setor público e privado vão além dos objetivos finais e devem ser consideradas desde a idealização do projeto. Pisa e Oliveira (2013) enumeram os critérios pertinentes ao setor público que divergem do privado, a saber: (1) o aspecto social existente nos projetos governamentais; (2) a obrigatoriedade de previsão de recursos, em lei, para execução de projetos públicos (Lei Orçamentária Anual - LOA); (3) o atendimento às especificações da Lei $n^{\circ} 8.666 / 93$, que trata das contratações públicas através de diversas modalidades e que prioriza o menor preço; (4) as diversas normatizações às quais os empreendimentos públicos estão submetidos; (5) o controle exercido por diferentes órgãos de todas as esferas de governo; (6) a prestação de contas públicas para atendimento ao princípio da transparência e às questões de accountability da governança pública.

Ainda segundo Pisa e Oliveira (2013), apesar dessas particularidades, o setor público brasileiro tem se utilizado das técnicas de gerenciamento de projetos para a melhoria não só da qualidade dos serviços prestados à sociedade, mas também do controle dos custos envolvidos, da eficiência na execução dos empreendimentos, das questões envolvendo a governança pública e dos resultados almejados pelos planos governamentais. Em especial 
quanto à governança, Pisa e Oliveira (2013) afirmam que a gestão de projetos é comprovadamente um instrumento eficiente neste quesito, uma vez que promove a rastreabilidade de todos os processos envolvidos por meio da documentação pormenorizada de todas as fases do projeto.

Especificamente em relação aos projetos de infraestrutura, Carvalho, Paula e Gonçalves (2017) salientam que, principalmente nos países em desenvolvimento, os desafios em relação à gestão de obras públicas têm sido majorados em virtude da crescente necessidade de obras de infraestrutura, com projetos cada vez mais exigentes e complexos. Os autores apontam as divergências de tempo em grandes obras públicas como um dos principais problemas a serem evitados, mas também ressaltam que não basta cumprir os prazos estabelecidos sem se atentar aos custos e ao cumprimento dos requisitos de qualidade do projeto.

\section{Procedimentos metodológicos}

A metodologia utilizada para elaboração deste trabalho foi exploratória, baseada na abordagem qualitativa, desenvolvida por meio de investigação, pesquisa de campo e estudo de caso, além de entrevistas informais (Alonso, Lima \& Almeida, 2016).

A pesquisa foi realizada na Empresa Brasileira de Infraestrutura Aeroportuária (Infraero), criada em 1973 com o propósito de prover e gerir a infraestrutura aeroportuária em todas as regiões do Brasil. Ao longo desses mais de 45 anos de existência, a Infraero atuou para melhorar a infraestrutura dos aeroportos brasileiros, assim como para prover as facilidades e a disponibilidade de serviços relacionados ao modal de transporte aéreo nacional e internacional. Para tanto, construiu e ampliou terminais de passageiros, pistas de pouso e decolagem, pistas de taxiamento, pátios de estacionamento de aeronaves e terminais de carga aérea.

Além disso, a Infraero estabeleceu os procedimentos para gestão e para a operação de aeroportos, em conformidade com os requisitos internacionais exigidos aos países signatários da Organização da Aviação Civil Internacional (OACI), internalizados no Brasil pela Agência Nacional de Aviação Civil (ANAC, 2009a, 2009b). Dessa forma, para que essa atuação fosse possível, a estatal criou metodologias de gestão específicas às características do ambiente aeroportuário, como é o caso da metodologia de gestão de projetos abordada neste trabalho (Infraero, 2012).

Para a coleta de dados, foram realizadas pesquisas bibliográficas, pesquisas documentais e entrevistas informais com os empregados do Aeroporto Internacional de Curitiba / Afonso Pena, localizado em São José dos Pinhais (PR).

A modalidade estudo de caso foi escolhida, pois, conforme Alonso, Lima e Almeida (2016), além de ser uma ferramenta específica de produção de dados a partir da análise e descrição de acontecimentos, é 
também uma estratégia que permite a combinação de diferentes metodologias qualitativas, como a observação, as entrevistas e a análise de registros históricos, utilizadas para elaboração deste estudo.

Quanto à natureza qualitativa, aplicada e com objetivo exploratório, Gerhardt e Silveira (2015) caracterizam como "qualitativa" a pesquisa realizada para aprofundamento da compreensão acerca do assunto pesquisado, cujos dados analisados são "não-métricos". Nesta pesquisa, foram analisados os aspectos da realidade que não podem ser quantificados. Já a natureza "aplicada" deve-se ao fato de os resultados gerarem conhecimento para aplicação prática e específica do assunto em questão. E, por fim, as autoras definem como "exploratória" a pesquisa, cujo objetivo é a familiarização do pesquisador com o tema, a fim de torná-lo mais claro.

Uma das técnicas utilizadas para a coleta de dados foi a pesquisa bibliográfica, baseada em artigos científicos sobre gerenciamento de projetos e no Guia PMBOK. Silva e Moura (2018) conceituam a pesquisa bibliográfica como o levantamento da literatura já publicada sobre o tema em livros, revistas, periódicos, páginas da internet, publicações avulsas, etc., a fim de colocar o pesquisador em contato direto com determinado assunto. Adicionalmente, foram realizadas análises documentais em normas, procedimentos e manuais elaborados pela Empresa Brasileira de Infraestrutura Aeroportuária - Infraero. Silva e Moura (2018) descrevem a análise documental justamente como aquela realizada em documentos internos produzidos pela instituição.

Quanto às entrevistas, Gil (2008) recomenda a entrevista informal para os estudos exploratórios, pois segundo o autor, este tipo de entrevista possibilita a obtenção de uma visão geral do problema pesquisado a partir das declarações dos entrevistados, que podem ser especialistas no tema em estudo, líderes formais ou informais, personalidades destacadas, etc. Para este trabalho, foram entrevistados engenheiros os quais fizeram parte da Equipe de Gestão do Projeto da obra de recuperação da pista de pouso e decolagem auxiliar do Aeroporto Internacional de Curitiba / Afonso Pena.

\section{Análise e discussão dos resultados}

\subsection{Metodologia de gerenciamento de projetos da Infraero}

\subsubsection{Manual de gerenciamento de projetos}

Em meados de 2012, a Diretoria de Engenharia da Infraero (responsável por todas as atividades de engenharia da estatal em nível nacional), objetivando elevar o nível de sucesso dos projetos conduzidos sob sua responsabilidade, publicou o seu próprio Manual de Gerenciamento de Projetos (MGP), estabelecendo um modelo padrão de gestão que passou a ser considerado como boa prática dentro da empresa. O MGP-Infraero, desenvolvido com base em metodologias consolidadas de gestão de projetos, como o 
Guia PMBOK do PMI, especifica o ciclo de vida de gerenciamento de projetos a ser conduzido pelo Gerente de Engenharia e pela Equipe de Gestão de Projetos das unidades aeroportuárias da rede Infraero, estabelecendo processos, formulários padronizados, ferramentas, técnicas, papéis e responsabilidades.

Considerando um "projeto" como um modelo de gestão, o MGP-Infraero estabeleceu como objetivos: aumentar o sucesso dos projetos executados pela empresa, em especial quanto ao cumprimento de prazos; esclarecer a definição e a comunicação das prioridades da empresa; aumentar a integração interfuncional; definir e atribuir papéis e responsabilidades aos empregados, considerando as competências requeridas para o pleno desempenho de suas atribuições; implantar uma metodologia própria de gerenciamento de projetos que possibilite o monitoramento e o controle da execução dos projetos em toda a rede de aeroportos administrada pela estatal; e introduzir processos e técnicas que propiciem benefícios efetivos à gestão aeroportuária.

A estatal adotou como conceito de projeto um esforço temporário, não rotineiro e com prazo definido, realizado para o desenvolvimento de estudos de engenharia, estudos ambientais ou obras de infraestrutura. Para cada projeto desenvolvido na empresa, há uma Equipe de Gestão de Projeto designada pelo Gerente de Engenharia e alocada como responsável pela execução dos processos de gerenciamento definidos no MGP. À Equipe de
Gestão de Projeto cabe executar os procedimentos estabelecidos pela Infraero visando ao sucesso do projeto, definido pela empresa como a entrega do estudo (de engenharia, ambiental ou a obra) dentro do prazo e do custo planejados, e com baixo índice de mudanças.

\subsubsection{Escritório de projetos e equipes de gestão de projetos}

O Guia PMBOK define um Escritório de Projetos (Project Management Office $P M O)$ como uma estrutura organizacional voltada à padronização dos processos de governança relacionados aos projetos da empresa, e ao compartilhamento de recursos, metodologias, ferramentas e técnicas (PMI, 2017)

O PMO da Infraero está fisicamente situado em Brasília (DF), na Sede da empresa. Sua finalidade é justamente facilitar o compartilhamento de recursos, metodologias, ferramentas e técnicas, além de desempenhar um papel consultivo nos projetos, fornecendo modelos, melhores práticas, treinamentos, acesso a informações e lições aprendidas em outros projetos realizados nos aeroportos administrados pela empresa. Além disso, seus integrantes são responsáveis pela conformidade dos processos de gerenciamento de projetos em relação à governança empresarial.

Considerando a abrangência nacional de atuação da Infraero, Gerências Temporárias são montadas nos aeroportos onde os projetos serão executados, funcionando como um braço 
do PMO na localidade onde são alocadas as Equipes de Gestão de Projetos até a entrega final de seus resultados. As Equipes de Gestão de Projetos são designadas pelo Gerente de Engenharia por meio de um Termo de Abertura do Projeto, tendo como funções: elaborar, monitorar e controlar a execução do planejamento do projeto; seguir os processos do ciclo de vida do gerenciamento do projeto estabelecidos no MGP da Infraero; atualizar semanalmente o cronograma do projeto com base nas informações fornecidas pelos fiscais operacionais dos contratos; promover reuniões também semanais com a empresa contratada a fim de ajustar desvios no cronograma; elaborar relatórios mensais sobre o desempenho do projeto; monitorar e controlar seus riscos; controlar as mudanças aprovadas e atualizar a documentação pertinente; fazer a ponte entre a Gerência Temporária e a governança do MGP para esclarecimento de dúvidas metodológicas ou sugestão de melhorias no decorrer do andamento do projeto; entre outras.

\subsubsection{Componentes e ciclo de vida do gerenciamento do projeto}

O modelo de gestão de projetos desenvolvido pela Infraero define um processo como um conjunto de ações e atividades que são executadas de forma interrelacionada para criação de um produto, serviço ou resultado previamente especificado, sendo caracterizado por suas entradas, ferramentas, técnicas e saídas resultantes. Os processos de gerenciamento de projetos garantem o fluxo eficaz do projeto ao longo de sua execução, abrangendo as ferramentas e técnicas descritas nas áreas de conhecimento.

O Manual, com base na edição vigente do PMBOK na época de sua elaboração, elenca 14 processos logicamente agrupados em cinco fases para gerenciamento dos projetos da empresa, que consistem em: iniciação; planejamento; execução; monitoramento e controle; e encerramento. Além disso, os processos de gerenciamento são também agrupados em 7 áreas de conhecimento: integração; escopo; tempo; custo; risco; comunicação; recursos humanos; e partes interessadas.

Cada área de conhecimento representa um conjunto completo de conceitos, termos e atividades que compõem um campo profissional, um campo de gerenciamento de projetos ou uma área de especialização. A integração de cada área de conhecimento com as cinco fases do projeto está definida no MGP (Infraero, 2012).

\subsection{Recuperação da pista de pouso e decolagem auxiliar}

Segundo a Infraero (2019), o Aeroporto Internacional de Curitiba / Afonso Pena possui vocação para os negócios, movimentando, diariamente, uma média de 20.100 passageiros, 210 voos e $81.327 \mathrm{~kg}$ de carga aérea. Seu sistema de pistas contém 2 pistas de pouso e decolagem e 10 pistas de táxi, além de 2 pátios de estacionamento de aeronaves com 26 posições de estacionamento. 
A pista de pouso e decolagem auxiliar (PPD 11/29) possui dimensões e características que permitem operações de aeronaves até categoria "C", na qual estão inseridas as aeronaves mais comumente utilizadas pelas empresas aéreas brasileiras para voos domésticos. Essa pista, no entanto, estava sendo utilizada por somente $1,6 \%$ do total de operações de pouso e decolagem do aeroporto devido às condições de desgaste natural do seu pavimento (Estatísticas Infraero, 2016). Dessa forma, com o objetivo de ampliar a capacidade de processamento do aeroporto, agilizar suas operações e possibilitar a expansão da aviação civil a partir da capital paranaense, a revitalização dessa pista era fundamental.

\subsection{Aplicação da metodologia}

\subsubsection{Iniciação}

O projeto foi iniciado pela Diretoria de Engenharia da Infraero com a elaboração do Termo de Abertura para contratação de obras de engenharia para recuperação do pavimento da pista de pouso e decolagem 11/29 do Aeroporto Internacional de Curitiba / Afonso Pena. Conforme o MGP da Infraero, a elaboração do Termo de Abertura do Projeto formaliza sua iniciação. É neste momento que a Equipe de Gestão do Projeto é nomeada e os patrocinadores são comprometidos com o escopo, com o prazo e com os custos aprovados para o projeto. $\mathrm{O}$ ideal, segundo consta no Manual, é que as Equipes de Gestão do Projeto designadas participem desde o desenvolvimento do Termo de Abertura do
Projeto, para que compreendam a base de requisitos do mesmo, definindo suas premissas, restrições e seu escopo inicial.

Nesta etapa inicial, de formação da Equipe de Gestão do Projeto, foi possível identificar a primeira melhoria proporcionada pela nova metodologia adotada pela Infraero. Antes da revitalização da PPD 11/29, o último grande empreendimento executado no Aeroporto Afonso Pena havia sido a ampliação do Terminal de Passageiros. Naquela ocasião, a equipe necessária foi composta por 65 profissionais, entre os quais técnicos lotados em outras localidades, que foram transferidos provisoriamente para a execução do projeto. Já para a revitalização da PPD 11/29, após a adoção da nova metodologia, foram suficientes apenas 3 profissionais, representando uma redução de 95\%, que refletiu diretamente na diminuição de custos, de burocracia, de trâmites documentais e processuais, e de interferências de forma geral, conforme informado pelo então Superintendente de Engenharia da empresa em entrevista concedida aos autores em $30 / 10 / 2019$.

O Termo de Abertura da obra em comento definiu como objetivos do projeto: a eliminação dos problemas do pavimento da PPD 11/29, com execução de obras compreendendo a reconstrução parcial de sua faixa central e de áreas de interface da pista com outros segmentos do aeroporto, como pistas de táxi de acesso; o recapeamento total da pista com reperfilamento do eixo e adequação das seções transversais aos padrões de projeto; e 
serviços complementares para viabilização dos itens anteriores. $\mathrm{O}$ escopo do projeto compreendeu ainda os serviços de drenagem subsuperficial do pavimento reconstruído e a nova pintura da sinalização horizontal na própria PPD e na interface com as pistas de taxiamento.

Como justificativa, a necessidade de a

PPD dispor de um pavimento que proporcionasse segurança operacional adequada às suas operações, dentro dos aspectos de integridade, regularidade, escoamento de água e coeficiente de atrito, além da compatibilização das condições estruturais com suas especificações operativas.

No Termo de Abertura, a Diretoria de Engenharia elencou, como expectativas do cliente, a obtenção de ganhos operacionais quanto:

Tabela 1 - Expectativas do cliente

\begin{tabular}{|l|l|}
\hline \multicolumn{1}{|c|}{ Aspectos } & \multicolumn{1}{c|}{ Expectativas } \\
\hline $\begin{array}{l}\text { Utilização da PPD 11/29 para processar um } \\
\text { maior número de operações. }\end{array}$ & $\begin{array}{l}\text { De 1,6\% do total de operações para até 15\% } \\
\text { (Estatísticas Infraero, 2016). }\end{array}$ \\
\hline $\begin{array}{l}\text { Redução do tempo de espera entre pousos e } \\
\text { decolagens no aeroporto. }\end{array}$ & $\begin{array}{l}\text { Distribuição das operações de apenas uma pista } \\
\text { para duas pistas de pouso e decolagem. }\end{array}$ \\
\hline $\begin{array}{l}\text { Maior fluidez na operação e ocupação dos } \\
\text { pátios de estacionamento de aeronaves. }\end{array}$ & $\begin{array}{l}\text { Utilização da pista auxiliar para o taxiamento de } \\
\text { aeronaves, liberando a pista principal e outras } \\
\text { pistas de táxi para as demais aeronaves. }\end{array}$ \\
\hline $\begin{array}{l}\text { Aceitação de mais voos, com consequente } \\
\text { aumento de receita financeira. }\end{array}$ & $\begin{array}{l}\text { No mínimo 13,4\% de acréscimo, considerando } \\
\text { apenas o processamento estimado para a PPD } \\
11 / 29 \text { (Estatísticas Infraero, 2016). }\end{array}$ \\
\hline $\begin{array}{l}\text { Diminuição dos custos de manutenção do } \\
\text { aeroporto. }\end{array}$ & $\begin{array}{l}\text { Distribuição das operações entre duas pistas, } \\
\text { reduzindo a sobrecarga da pista principal. }\end{array}$ \\
\hline
\end{tabular}

Fonte: Infraero

Foram definidas como premissas do projeto: a disponibilização de horários diurnos contínuos para a execução das obras com o aeroporto em funcionamento; a disponibilização de uma "janela operacional" (intervalo de tempo sem operações no aeroporto) de, pelo menos, 6 horas contínuas durante a madrugada para execução dos trabalhos em áreas onde ocorreria interferência na pista de pouso e decolagem principal e pistas de taxiamento interligadas; a liberação de áreas incluídas no escopo para realização das atividades da obra e movimentação de equipamentos e de pessoal; a montagem de um canteiro de obras dentro da área operacional do aeroporto, onde deveriam ficar os equipamentos com menor mobilidade, próximo à área de obras; a disposição dos resíduos de fresagem e de demolição do pavimento antigo da pista em áreas internas do sítio aeroportuário; a elaboração de procedimentos específicos de segurança operacional, a serem observados pela empresa contratada para garantia da segurança das operações durante o andamento da obra; além dos licenciamentos ambientais cabíveis.

Por fim, o Termo de Abertura identificou as partes interessadas no projeto e definiu seus responsáveis: os representantes 
operacionais do Aeroporto Afonso Pena (gestor do aeródromo e os responsáveis pela segurança operacional, pelas operações aeroportuárias, pela manutenção aeroportuária e pela resposta a emergências); a Diretoria de Engenharia da Infraero e a área de governança da empresa; os órgãos ambientais relacionados; a ANAC; o Destacamento de Controle do Espaço Aéreo de Curitiba - DTCEA-CT, responsável pela Torre de Controle (TWR-CT) de navegação aérea no aeroporto; as empresas aéreas que operam regularmente no Aeroporto Afonso Pena; e os próprios usuários do aeroporto.

O Manual da Infraero define as partes interessadas como aquelas que podem impactar ou serem impactadas por uma decisão, atividade ou resultado do projeto. A identificação dessas partes inclui a análise e a documentação de informações referentes a seus interesses, expectativas, nível de engajamento e de influência, bem como ao impacto que podem causar no sucesso do projeto.

A Infraero considera fundamental que as partes interessadas sejam identificadas desde o início do projeto, devendo haver revisões e atualizações regulares, ao longo do ciclo de vida do projeto, da análise inicialmente realizada. Além disso, como a maioria dos projetos possui um número elevado de partes interessadas, o Manual orienta que, após a identificação das partes interessadas, estas sejam classificadas conforme seu interesse, influência e envolvimento no projeto, de forma a permitir que a Equipe de Gestão do Projeto foque nos relacionamentos que são realmente imprescindíveis à garantia do sucesso do projeto.

\subsubsection{Planejamento}

O planejamento do projeto foi iniciado pela elaboração da Estrutura Analítica de Projeto (EAP), uma decomposição hierárquica orientada às entregas, que reflete o escopo total do projeto. É composta por:

1. Planejamento: incluindo a própria EAP e o cronograma físico-financeiro;

2. Plano de Controle Ambiental de Obra (PCAO): desenvolvido com o objetivo de minimizar os impactos ambientais gerados pelos processos construtivos e reduzir os passivos ambientais, normalmente gerados na fase de implementação dos empreendimentos;

3. Projeto Executivo (PE): conjunto de elementos necessários e suficientes à execução completa da obra, de acordo com as normas técnicas pertinentes;

4. Administração local, operação e manutenção do canteiro: equipe técnica mantida pela empresa contratada no local da obra, permanentemente à disposição da Infraero, que será também responsável pela adequada manutenção, operação, limpeza, vigilância e boa apresentação do canteiro de obras e de todas as suas instalações, observando os requisitos da legislação brasileira de aviação civil e demais legislações cabíveis; 
5. Canteiro de obra: pacote de serviços referente à área de trabalho fixa e/ou temporária, onde se desenvolvem as operações de apoio e execução da obra, divididas em áreas operacionais e de vivência;

6. Mobilização e desmobilização: a mobilização consiste no conjunto de providências a serem adotadas visando ao início da obra, enquanto que a desmobilização consiste na desmontagem e na retirada das estruturas, construções, equipamentos e limpeza geral do local;

7. Obras de infraestrutura: subdivididas em serviços preliminares (demolições, remoções, adequações da infraestrutura para manutenção da operação do aeroporto de forma a não inviabilizar a movimentação das aeronaves, caminhos de serviço - abertura, manutenção e recomposição) e as fases propriamente ditas (limpeza, terraplanagem, pavimentação, drenagem, sinalizações, atividades complementares, ensaios e testes, etc.);

8. As Built: conjunto de documentos de projeto revistos, atualizados e completamente detalhados (especificação técnica, representação gráfica, memorial descritivo), refletindo com exatidão como o projeto foi efetivamente implementado;

9. Comissionamento, operação assistida e certificações: atividades técnicas a serem executadas pela contratada, sob a supervisão da fiscalização da obra, para avaliação da conformidade dos serviços executados, a fim de receber o ativo em condições operacionais;

10. Serviços finais: atividades finais referentes à execução da obra, a fim de deixar o canteiro de obras apto a receber as vistorias finais para posterior entrega à Infraero, além da limpeza final da obra e posterior remoção do canteiro de obras, com demolição seletiva e recomposição das áreas degradadas, limpeza e recomposição dos locais utilizados; e

11. Vistoria e recebimento: objetivando verificar as condições construtivas do projeto no seu recebimento e analisar a sua conformidade com os documentos do projeto.

Ou seja, a EAP subdivide as entregas e o trabalho em componentes menores, com o intuito de facilitar seu gerenciamento, organizando e definindo o escopo total do projeto aprovado. Contém todo (e somente) o trabalho necessário para a realização do escopo, devendo incorporar as alterações realizadas ao longo da execução do projeto. A Infraero considera que o sucesso do projeto está vinculado à execução de todos os componentes da EAP.

O cronograma também foi definido durante a etapa de planejamento, incluindo os serviços iniciais (mobilização, instalação do 
canteiro de obras e as atividades de administração local e de manutenção do canteiro), os serviços a serem realizados (serviços preliminares, terraplanagem, pavimentação, drenagem subsuperficial e outros serviços diversos), a pintura da sinalização horizontal e instalação da sinalização luminosa (luminárias, aterramento e infraestrutura necessária) e os serviços complementares (as built e desmobilização).

Para o desenvolvimento do cronograma é necessário analisar a sequência dos pacotes de trabalhos e de entregas quanto à sua duração, aos recursos necessários e às suas restrições. Trata-se de um processo iterativo que define datas planejadas para início e fim das atividades e marcos do projeto. O Manual da Infraero define uma sequência que deve ser seguida para a elaboração do Cronograma do Projeto:

1. Definição dos pacotes de trabalho por meio da identificação das entregas específicas que deverão ser realizadas para produção do escopo do projeto;

2. Sequenciamento dos pacotes de trabalho por intermédio da identificação e da documentação dos relacionamentos entre os mesmos;

3. Estimativa dos recursos disponíveis para os pacotes de trabalho (recursos orgânicos da empresa);

4. Estimativa da duração dos pacotes de trabalho definida com base no número aproximado de dias necessários para conclusão de pacotes específicos, considerando os recursos disponíveis estimados;

5. Otimização do cronograma a partir da análise das sequências dos pacotes de trabalho, suas durações, suas necessidades de recursos e suas restrições, visando à criação de um cronograma compacto para o projeto.

O cronograma deve refletir a última linha de base aprovada no processo de controle integrado de mudanças, e todos os membros da Equipe de Gestão do Projeto devem ter pleno conhecimento do item que está sendo executado, bem como de seus prazos, atrasos, alterações e dependências. A Infraero considera que o cronograma é uma ferramenta basilar do planejamento, e que deve ser utilizada como guia diário durante a execução do projeto.

Para avaliação do desempenho e subsídio à tomada de decisões, uma linha base de medição deve ser definida por meio da combinação do escopo, do cronograma e do orçamento do projeto, resultando em uma curva de planejamento do valor agregado ao longo de sua execução. De acordo com o MGP, para definição da linha de base de medição é necessário primeiro estimar os custos dos recursos que serão utilizados no projeto e determinar seu orçamento. Os custos incluem desde os recursos básicos, como mão-de-obra, materiais, equipamentos, serviços e instalações, até custos diversos com contingências e inflação, por exemplo. Já o orçamento consiste na agregação desses custos estimados. A partir 
da linha base de medição é possível comparar o avanço do escopo em relação ao cronograma e aos orçamentos planejados, permitindo à Equipe de Gestão do Projeto visualizar facilmente o seu desempenho.

$\mathrm{Na}$ obra de recuperação da pista auxiliar, a forma de medição de cada tipo de serviço foi definida nos documentos "Especificação Técnica Específica (ETE)" e “Especificação Técnica Geral (ETG)”, ambos componentes do Termo de Referência para contratação da obra. Enquanto a ETE tem como objetivo detalhar tecnicamente os serviços que deverão ser executados, definindo conceitos, procedimentos, parâmetros de aceitação e critérios de medição, a ETG apresenta diretrizes gerais e procedimentos formais que deverão ser seguidos pela empresa contratada no decorrer dos serviços, bem como detalhes sobre a equipe técnica mínima, sobre as atribuições e responsabilidades da contratante e da contratada, além de critérios de fiscalização dos trabalhos.

Ambos os documentos são essenciais para diferenciação dos requisitos de uma obra de recuperação asfáltica de uma rodovia, por exemplo, para uma obra de recuperação asfáltica de uma pista de pouso e decolagem. A ETE da obra de recuperação da PPD 11/29 explicita desde os requisitos específicos para a pavimentação (tipo de material, composição, granulometria, temperatura de aplicação, forma de aplicação, etc.), o coeficiente de atrito mínimo resultante, o índice de irregularidade longitudinal máximo, o tipo de sistema de drenagem subsuperficial, até a quantidade de microesferas que deverá ser aplicada na pintura da sinalização horizontal, conforme requisitos da legislação vigente para as operações aeronáuticas que serão realizadas nessa pista de pouso e decolagem.

Já a ETG detalha os critérios pertinentes ao ambiente aeroportuário, como procedimentos específicos de segurança operacional durante a execução das atividades na área operacional do aeroporto, requisitos para credenciamento e acesso a áreas restritas de segurança federal e necessidade de treinamentos especiais à equipe da contratada (radiocomunicação, fraseologia aeronáutica padrão, procedimentos de evacuação de emergência, direção defensiva em aeroportos, acesso e permanência em área de manobras de aeronaves, operações em baixa visibilidade, etc.).

Compõe também os documentos do projeto: o Memorial Descritivo (MD), com a apresentação das condicionantes dos serviços, do programa de necessidades para a obra, das orientações gerais da Infraero, da normatização aplicável e dos documentos de referência; a Planilha de Quantidades de Serviços (PQS), com a descrição dos itens de serviços e suas quantidades; o Plano Geral de Pavimentação, com o desenho do sistema de pistas e pátios do aeroporto; além de diversas plantas necessárias para apresentação de perfis de drenagem, da sinalização horizontal, do projeto geométrico e perfil longitudinal, das seções transversais do 
projeto, do balizamento luminoso, da sinalização vertical, etc.

$\mathrm{Na}$ fase de planejamento, foi elaborada uma planilha para gerenciamento dos riscos e das oportunidades relacionadas à obra. A elaboração dessa planilha envolve a identificação, a qualificação, a quantificação e o planejamento de respostas adequadas aos riscos e às oportunidades identificados. Segundo o MGP, a identificação consiste na determinação dos riscos e das oportunidades capazes de afetar o projeto, e na documentação de suas características. A qualificação é a priorização desses riscos e oportunidades por meio da combinação da probabilidade de ocorrerem com a severidade de seus impactos, objetivando reduzir os níveis de incerteza do projeto e permitir à Equipe de Gestão focar nos riscos e oportunidades de maior prioridade (Infraero, 2012).

Já a análise quantitativa refere-se ao levantamento numérico dos efeitos dos riscos e das oportunidades identificados nos objetivos gerais do projeto, com a finalidade de subsidiar a tomada de decisões, também reduzindo os níveis de incerteza da Equipe de Gestão do Projeto. E por fim, o planejamento das respostas adequadas consiste no desenvolvimento de medidas capazes de aumentar as oportunidades e reduzir os riscos, adequando o orçamento e o cronograma conforme necessário, de acordo com o MGP (Infraero, 2012).

O principal risco identificado no projeto da obra de recuperação da PPD 11/29 foi o não cumprimento do cronograma, pois afetaria diretamente o compromisso firmado entre o aeroporto e as partes interessadas. Diversas causas foram elencadas para um eventual não cumprimento de cronograma, como: problemas na licitação, insuficiência operacional da empresa contratada (por falta de mão-de-obra, de insumos, de capacidade de atendimento aos requisitos da ETE, etc.), atrasos dos fornecedores de materiais e equipamentos específicos (placas de sinalização vertical, peças importadas do balizamento luminoso, etc.).

Por outro lado, diversas oportunidades também foram prospectadas pela Equipe de Gestão do Projeto, como a utilização de novas tecnologias para pavimentação, que estavam despontando no mercado, e a possibilidade de melhoria dos sistemas de iluminação da PPD $11 / 29$, por intermédio da substituição das luminárias antigas por luminárias com tecnologia LED (maior vida útil e menor consumo de energia).

$\mathrm{E}$, finalizando a fase de planejamento, a Diretoria de Engenharia designou, por ato formal, o Gerente de Engenharia e a Equipe de Gestão do Projeto, definindo suas atribuições e responsabilidades.

\subsubsection{Execução}

Para a Infraero, estabelecer uma comunicação eficaz com as partes interessadas é um fator crítico para o sucesso de um projeto. A partir da distribuição das informações é possível garantir que as prioridades, os 
problemas e os objetivos serão compreendidos por todas as pessoas envolvidas no projeto.

Para a execução da obra em análise foram necessárias ações integradas das partes interessadas, uma vez que o aeroporto manteve suas operações (passageiros e carga) praticamente inalteradas ao longo dos 12 meses de obra. Para que isso fosse possível, a Infraero dividiu as atividades em 3 etapas:
ETAPA 1: Interdição da PPD 11/29 para execução das atividades durante o dia, no trecho compreendido entre a cabeceira 29 até 140 metros do eixo da pista principal, distância esta que possibilita a continuidade das operações na pista principal, sob qualquer condição de visibilidade (Infraero, 2017):

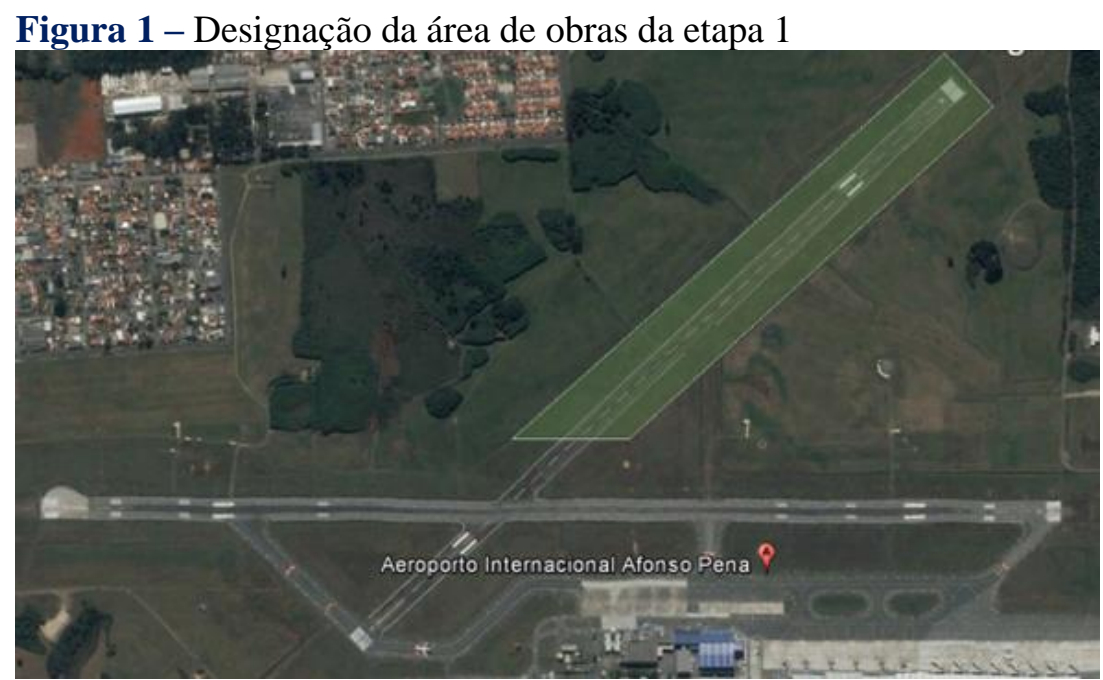

Fonte: Infraero / Aeroporto Internacional de Curitiba / Afonso Pena.

ETAPA 2: Nos trechos compreendidos entre 140 metros a 75 metros do eixo da pista principal, à esquerda da runway 15 , e entre 75 metros do eixo da pista principal até 43,5 metros do eixo das taxiways "A" e "C", à direita da runway 15, as atividades só puderam ser realizadas nos momentos em que o aeroporto estava operando em condições visuais, conforme disposto no RBAC 154 EMD 02, item 154.207(c)(3)(i) (Infraero, 2017): 


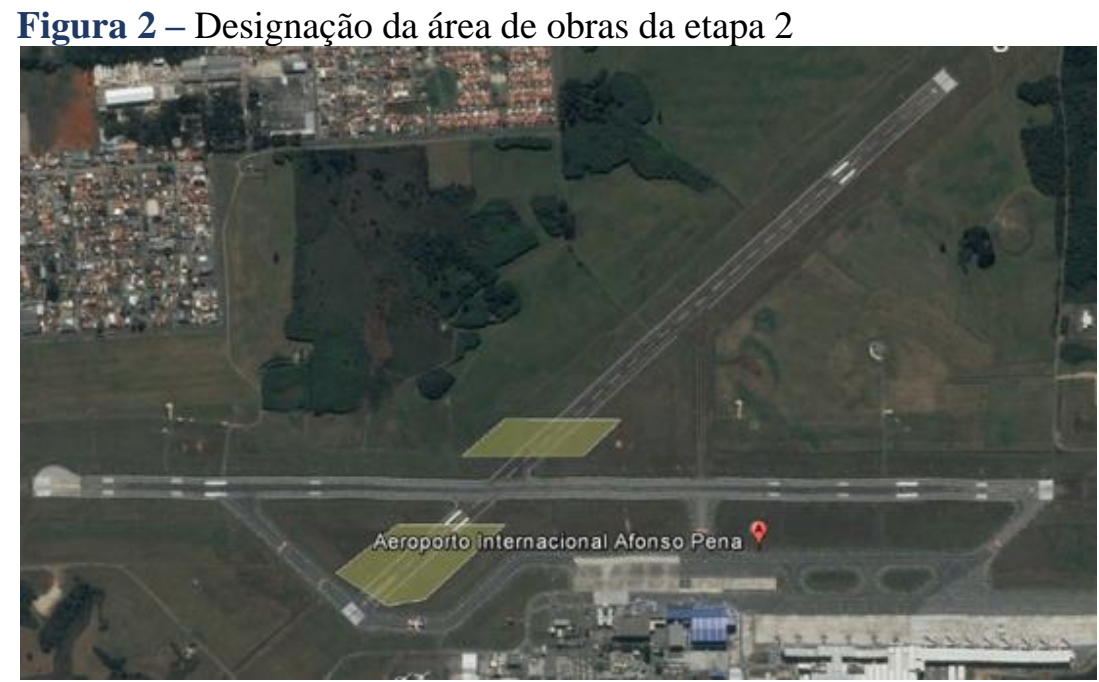

Fonte: Infraero / Aeroporto Internacional de Curitiba / Afonso Pena.

ETAPA 3: Os trechos compreendidos até 75 metros do eixo da pista principal, para ambos os lados, só puderam ser realizados durante as janelas operacionais da madrugada, com interdição de ambas as pistas de pouso e decolagem. E o trecho a partir de 43,5 metros do eixo das pistas de táxi "A" e "C", mais precisamente na cabeceira 11 , foi realizado com interdição da PPD 11/29 e de ambas as pistas de táxi, mantendo-se as operações na pista principal (Infraero, 2017):

Figura 3 - Designação da área de obras da etapa 3

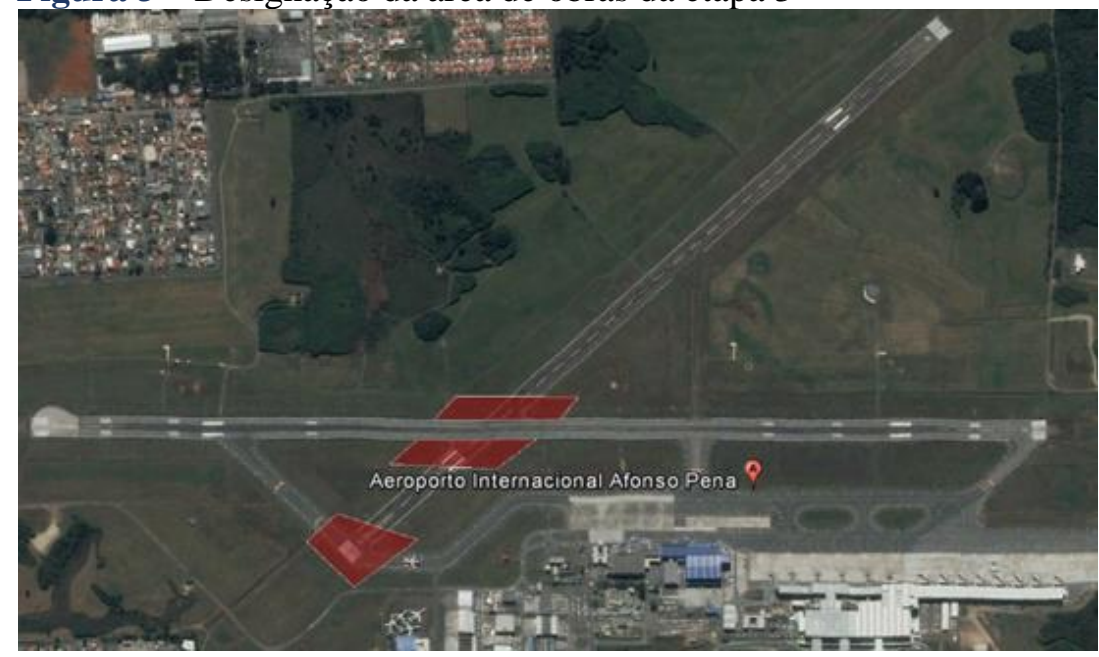

Fonte: Infraero / Aeroporto Internacional de Curitiba / Afonso Pena.

Durante a execução das atividades, a Equipe de Gestão do Projeto lidou com algumas situações bem específicas do ambiente aeroportuário, por exemplo: em condições de baixa visibilidade (alcance visual de pista de pouso e decolagem inferior a 350 metros, conforme item 153.1-44 do RBAC 153 EMD 04), procedimentos especiais para garantia da segurança das operações entram em vigor, entre os quais a interrupção de todas as atividades não 
essenciais às operações aeronáuticas, inclusive obras.

A região de São José dos Pinhais, Paraná, onde está situado o Aeroporto Afonso Pena, é frequentemente atingida por nevoeiros que provocam a condição de baixa visibilidade. Um outro exemplo: prorrogação do início da interdição da pista de pouso e decolagem devido ao atraso de um voo. Se a interdição estava programada para começar às $00 \mathrm{~h}$, por exemplo, porém o voo que deveria ter chegado às 23h50min encontra-se atrasado, pode ser necessária uma coordenação entre a empresa aérea, o operador do aeródromo e a Torre de Controle para prorrogação do início da interdição, a fim de possibilitar o pouso da aeronave.

Atrasos poderiam ser de poucos minutos, como até de 1 hora ou mais. Consequentemente, a equipe da empresa contratada precisava aguardar o pouso, para então iniciar a mobilização para o local de obra. Se o mesmo voo atrasasse diariamente em torno de 1 hora, ao longo de uma semana seriam, pelo menos, 7 horas a menos de produtividade, o que poderia impactar significativamente no cronograma.

\subsubsection{Monitoramento e controle}

Um dos principais processos desta etapa é o controle do cronograma. É realizado por meio do monitoramento das atividades do projeto, atualização de informações sobre seu andamento e progresso, e gerenciamento das mudanças realizadas na linha de base do cronograma para efetivação do seu planejamento. Requer o conhecimento real do desempenho do projeto, por isso é importante a definição de indicadores de desempenho que contribuam para a avaliação do avanço do cronograma.

Outro processo fundamental nesta etapa é o monitoramento e controle dos riscos e das oportunidades. É nesta etapa que são implementados os planos de respostas definidos na fase de planejamento. Por conseguinte, são identificados novos riscos e oportunidades, bem como riscos residuais que devem ser mitigados. É também nesta etapa que as premissas do projeto são reavaliadas, que é feita a avaliação de eficácia do gerenciamento dos riscos, e que se confirma a observância às políticas e procedimentos da empresa. A Infraero considera esse processo essencial e determina sua execução durante todo o ciclo de vida do projeto.

Na prática, durante a execução da obra da pista auxiliar foi necessário atualizar os documentos do projeto em virtude de mudanças ocorridas. A primeira delas foi em relação às técnicas de pavimentação. Diferentemente do que estava preconizado na ETE, a empresa contratada propôs que a repavimentação da pista auxiliar fosse realizada por um equipamento novo, com tecnologia 3D, chamado de Trimble Paving Control Systems (PCS900 3D for Pavers).

A nova tecnologia dispensou o método convencional, que utiliza estacas e cabos de aço, identificando automaticamente a quantidade de 
material a ser aplicado, com base no projeto 3D e na posição em que o equipamento se encontrava em campo, garantindo assim a regularidade da camada superficial e, consequentemente, elevando a produtividade.

A segunda atualização se deu por conta da oportunidade de melhoramento do sistema elétrico da pista auxiliar. Uma vez que todas as bases e cabeamentos teriam que ser removidos para a recuperação da pista, a Infraero aproveitou a oportunidade para substituir a tecnologia antiga (lâmpadas halógenas convencionais) pela tecnologia LED. Além disso, houve o reposicionamento das bases das luminárias da pista, aproximando-as. Como dois circuitos intercalados alimentam as luminárias, caso um circuito falhe, a maior proximidade entre as bases possibilitará a continuidade operacional da pista de pouso e decolagem. A tecnologia em LED também foi empregada nas placas de sinalização vertical, em substituição às placas com iluminação fluorescente convencional. Essas alterações foram aprovadas para alinhamento com as políticas da empresa de adoção de tecnologias sustentáveis em seus empreendimentos, além de trazerem ganhos com economia de energia, menores custos de manutenção durante a vida útil dos equipamentos e uniformidade da iluminação, com padrões de qualidade internacionais.

No entanto, nem todas as alterações representaram melhorias. Também houve necessidade de adequações no controle do cronograma devido ao atraso na entrega de equipamentos importados. A fornecedora americana $A D B$ Safegate Airport Systems, a maior fornecedora de equipamentos e materiais específicos para aeroportos do mundo, atrasou suas entregas globais, causando um impacto de aproximadamente 5 meses no cronograma da obra, conforme dados dos relatórios de desempenho da Equipe de Gestão do Projeto. Felizmente, o ganho de produtividade proporcionado pelo emprego da tecnologia 3D durante a repavimentação da pista auxiliar compensou esse atraso.

\subsubsection{Encerramento}

Conforme o MGP da Infraero, um projeto é encerrado após a elaboração do Termo de Encerramento, que documenta a revisão de todos os processos realizados durante a execução do projeto, comparando-se o realizado ao previsto. É também nesta fase que se consolida o banco de lições aprendidas, que é um dos elementos mais importantes do gerenciamento de projetos, uma vez que armazena as experiências de sucesso e de fracasso que subsidiarão as decisões relacionadas a projetos futuros.

O Manual da Infraero classifica as lições aprendidas como positivas ou negativas. No cadastro de lições aprendidas positivas são registradas oportunidades de melhorias e boas práticas que contribuíram para o sucesso de projetos já concluídos. Já no cadastro de lições aprendidas negativas são registradas as causas dos fracassos e sugestões de alterações que devem ser realizadas para evitar sua 
recorrência. Tanto os registros positivos quanto os negativos devem ser realizados ao término de cada fase do projeto e consolidados ao final do projeto em um banco de dados compartilhado internamente na empresa.

Iniciada em março de 2018, a obra de recuperação da pista de pouso e decolagem auxiliar do Aeroporto Internacional de Curitiba / Afonso Pena foi oficialmente entregue pela então presidente da estatal, Martha Seillier, em abril de 2019. Todo o escopo do projeto foi executado e melhorias foram realizadas aproveitando-se oportunidades identificadas ao longo de sua execução. Apesar das alterações mencionadas anteriormente, o projeto foi entregue dentro do prazo e do custo planejado, caracterizando-se, portanto, como um sucesso.

Quanto às lições aprendidas, ressalta-se que a metodologia não se restringe à área de engenharia da empresa, porém abrange todas as partes interessadas da organização. A obra em questão teve duração de 12 meses e não gerou impacto algum aos usuários do aeroporto. Entre as principais lições aprendidas, destaca-se a otimização de utilização do sistema de pistas do aeroporto por intermédio da adoção de rotas padronizadas para as aeronaves, estipuladas pela área de operações da Infraero em coordenação com a Torre de Controle de Curitiba, que possibilitaram tanto a movimentação ágil das aeronaves em solo quanto a continuidade das atividades da obra, de forma segregada, sem prejuízos à segurança operacional.

\section{Conclusões}

Segundo o Guia PMBOK, um projeto bem-sucedido é aquele concluído dentro dos limites pré-definidos de prazo e de custos, e em conformidade com o escopo, a qualidade, os recursos e os riscos planejados (PMI, 2017). Já o Manual de Gerenciamento de Projetos da Infraero (2012) define o sucesso de um projeto como sendo a entrega do estudo (de engenharia, ambiental ou a obra) dentro do prazo e do custo planejados, e com baixo índice de mudanças. Diante desses critérios, a obra de recuperação da pista de pouso e decolagem auxiliar do Aeroporto Internacional de Curitiba / Afonso Pena foi concluída com sucesso e configura-se como um bom exemplo da aplicação efetiva da metodologia de gerenciamento de projetos desenvolvida pela empresa, com base no Guia PMBOK.

A metodologia, baseada na experiência da estatal - responsável pelo desenvolvimento da infraestrutura aeroportuária brasileira por mais de 45 anos - e na $4^{\mathrm{a}}$ e na $5^{\mathrm{a}}$ edição do Guia PMBOK, é constituída pelas melhores práticas, na concepção da Infraero, para gerenciamento de projetos. Adequada às especificidades das demandas da empresa, tanto em relação à infraestrutura quanto aos serviços aeroportuários, engloba ainda os critérios elencados por Pisa e Oliveira (2013) quanto às peculiaridades dos projetos públicos, levando em consideração: os benefícios e demais aspectos sociais inerentes aos projetos governamentais; a previsão de recursos, em lei, para a execução dos projetos; os critérios da lei 
de licitações (Lei $n^{\circ}$ 8.666/93); os diversos normativos que devem ser observados para execução de empreendimentos públicos; a prestação pública de contas à sociedade, aos órgãos reguladores e de controle, em atendimento aos princípios da transparência e às questões de accountability da governança pública.

Como pôde ser constatado por meio do exemplo abordado neste estudo, a metodologia de gerenciamento de projetos da Infraero contribui não só para o alcance dos objetivos dos seus projetos, como também para a melhoria da qualidade dos seus produtos finais, para um controle mais efetivo dos custos envolvidos, para o aumento da eficiência em suas execuções e para a melhoria do compliance em relação à governança e ao planejamento estratégico da empresa.

Por fim, para futuros estudos, sugere-se uma análise crítica comparativa entre as metodologias utilizadas por diferentes instituições públicas para gestão de projetos e sua compatibilização para elaboração de um guia próprio, a partir do qual seja possível compartilhar as melhores práticas desenvolvidas no Brasil, exemplos de sucessos, lições aprendidas e todo o know-how adquirido em prol da melhoria contínua dos processos da administração pública.

\section{Agradecimentos}

Agradecemos expressamente aos avaliadores da Revista de Gestão e Projetos -
GeP por suas recomendações, que contribuíram efetivamente para a ampliação e melhoria do desenvolvimento das ideias deste trabalho, bem como para nosso aprendizado e aperfeiçoamento acerca da produção científica.

\section{Referências}

ANAC - Agência Nacional de Aviação Civil. (2009a). Regulamento Brasileiro da Aviação Civil-RBAC $n^{\circ} 153$ Emenda $n^{\circ} 04$. Recuperado em 27 out., 2019 de https://bit.ly/36CIOHE

ANAC - Agência Nacional de Aviação Civil. (2009b). Regulamento Brasileiro da Aviação Civil-RBAC $n^{\circ} 154$ Emenda $n^{\circ} 06$ - Projeto de aeródromos. Recuperado em 27 out., 2019 de https://bit.ly/36I1aa8

ALLEMAN, G. B. (2003). Balanced Scorecard Conference: using balanced scorecard to build a project focused IT organization. IQPC 2003: International Quality \& Productivity Center, San Francisco, CA, 2830 oct.

ALONSO, A., LIMA, M., \& ALMEIDA, R. de. (2016). Métodos de pesquisa em Ciências Sociais: Bloco Qualitativo. CEBRAP. São Paulo, SP: Sesc São Paulo.

BASGAL, D. O., MEROTTO, M., MARTINS, P. M. O., CATARINO, B. R., NAVARRO, C. A. Z., \& GREGÓRIO, F. P. (2009). Scoring: um método prático e simples para priorização de projetos. Mundo PM Project Management, 5 (29), 24-27.

BOMFIN, D. F., NUNES, P. C. A., \& HASTENREITER, F. (2012).

Gerenciamento de projetos segundo o Guia PMBOK: desafios para os gestores. Revista de Gestão de Projetos - GeP, 3 (3), 58-87. DOI:10.5585/gep.v3i3.78

CARVALHO, M. T. M., PAULA, J. M. P., \& GONÇALVES, P. H. (2017).

Gerenciamento de obras públicas e as 
políticas de infraestrutura do Brasil contemporâneo. Instituto de Pesquisa Econômica Aplicada - IPEA. Recuperado em 22 out., 2019 de http://repositorio.ipea.gov.br/handle/11058/8 555

INFRAERO - Empresa Brasileira de Infraestrutura Aeroportuária. (2016). Estatísticas. Recuperado em 30 set., 2019 de https://transparencia.infraero.gov.br/estatisti cas

INFRAERO - Empresa Brasileira de Infraestrutura Aeroportuária. (2017). Procedimentos Específicos de Segurança Operacional - PESO $n^{\circ}$ 007/SBCT/2017. São José dos Pinhais, PR: Infraero.

INFRAERO - Empresa Brasileira de Infraestrutura Aeroportuária. (2019). Aeroporto Internacional de Curitiba / Afonso Pena. Recuperado em 30 set., 2019 de https://bit.ly/2PSI4Yd

INFRAERO - Empresa Brasileira de Infraestrutura Aeroportuária. (2012). MGP Manual de Gerenciamento de Projetos. Recuperado em 25 ago., 2019 de http://b.link/stream451

GERHARDT, T. E., \& SILVEIRA, D. T. (2009). Métodos de pesquisa. Porto Alegre, RS: Editora da UFRGS.

GIL, A. C. (2008). Métodos e técnicas de pesquisa social. (6a ed.). São Paulo, SP: Editora Atlas.

MARCONDES, A. (2017). Uma breve história do gerenciamento de projetos. Project Management Institute, Inc. Recuperado em 02 out., 2019 de http://pmimt.org.br/site/index.php/artigo/vis/ 4

MENESES, R. S., OLIVEIRA, L. G. L., \& VASCONCELOS, T. J. M. (2016). O gerenciamento de projetos em um Tribunal de Justiça: análise dos prazos dos projetos estratégicos 2010-2014. Revista de Gestão de Projetos - GeP, 7(3), 93-107.

MENEZES, L. C. M. (2001). Gestão de Projetos. São Paulo, SP: Atlas.

MICHALOSKI, A. O., COSTA, A. P. C. S. (2010). A survey of it use by small and médium-sized construction companies in a city in Brazil. ITcon - Journal of Information Technology in Construction, 15 (28), 369-390.

MICHALOSKI, A. O., \& COSTA, A. P. C. S. (2011). Modelo de diagnóstico do uso da TI para gestão de pequena e média empresa de construção civil. UFPE, Recife, PE. Recuperado em 22 mai., 2020 de https://repositorio.ufpe.br/handle/123456789 15058

PISA, B. J., \& OLIVEIRA, A. G. (2013). Gestão de projetos na administração pública. Seminário Nacional de Planejamento e Desenvolvimento. Recuperado em 28 set., 2019 de https://bit.ly/36Gec7W

PMI - Project Management Institute. (2017). Um guia do conhecimento em gerenciamento de projetos (Guia PMBOK). (6a ed.). PMI: Newtown Square, PA.

PMI - Project Management Institute. (2019). $O$ que é Gerenciamento de Projetos? Recuperado em 30 ago., 2019 de https://brasil.pmi.org/brazil/AboutUS/WhatI sProjectManagement.aspx

SILVA, A. M., \& MOURA, E. M. (2018). Metodologia do trabalho científico. (3a ed.). Fortaleza, CE: Ed. UECE.

XAVIER, C. M. S. (2016). Gerenciamento de projetos: como definir e controlar o escopo do projeto. (3a ed.). São Paulo, SP: Saraiva. 